\title{
Migrant Networks and Foreign Direct Investment
}

\author{
Beata S. Javorcik,* Çağlar Özden,* Mariana Spatareanu** \& Cristina Neagu*
}

\begin{abstract}
While there exists a sizeable literature documenting the importance of ethnic networks for international trade, little attention has been devoted to studying the effects of networks on foreign direct investment (FDI). The existence of ethnic networks may positively affect FDI by promoting information flows across international borders and by serving as a contract enforcement mechanism. This paper investigates the link between the presence of migrants in the United States and U.S. FDI in the migrants' countries of origin, taking into account the potential endogeneity concerns. The results suggest that US FDI abroad is positively correlated with the presence of migrants from the host country. The data further indicate that the relationship between FDI and migration is driven by the presence of migrants with a college education.
\end{abstract}

World Bank Policy Research Working Paper 4046, November 2006

The Policy Research Working Paper Series disseminates the findings of work in progress to encourage the exchange of ideas about development issues. An objective of the series is to get the findings out quickly, even if the presentations are less than fully polished. The papers carry the names of the authors and should be cited accordingly. The findings, interpretations, and conclusions expressed in this paper are entirely those of the authors. They do not necessarily represent the view of the World Bank, its Executive Directors, or the countries they represent. Policy Research Working Papers are available online at http://econ.worldbank.org.

* Development Economics Research Group (DECRG), World Bank MC3-303, 1818 H Street, NW, Washington, DC 20433; Email: bjavorcik@worldbank.org, cozden@worldbank.org and ineagu@worldbank.org, respectively.

** Department of Economics, Rutgers University, 801 Hill Hall, Newark, NJ 07102. Email: marianas@andromeda.rutgers.edu.

The authors would like to thank David McKenzie for sharing the data on passport fees and Torfinn Harding, Molly Lipscomb and participants of the World Bank international trade seminar for helpful comments and suggestions. 


\section{Introduction}

The decline in transportation and communications costs and the reduction in policy induced barriers have led to a rapid increase in the flow of goods, capital, people and knowledge across international boundaries. There exists an extensive literature exploring the effects of these forces, but much less attention has been paid to more subtle linkages and feedback mechanisms which are shaping the global economy. One of such linkages is the influence of migration on foreign direct investment (FDI), which is the focus of this study.

While a growing literature has documented a positive association between the presence of ethnic networks and international trade, the link between migration and FDI remains relatively unexplored. The main premise of the existing literature is that international transactions are plagued with informal trade barriers, in addition to formal trade barriers such as transportation costs and tariffs. Among these barriers are the difficulties associated with provision of information on many issues, including potential market opportunities, and with enforcing contracts across national boundaries. As shown by Gould (1994), Head and Ries (1998), Rauch and Trindade (2002) and Combes et al. (2003), the presence of people with the same ethnic background on both sides of a border may alleviate these problems. Their language skills and familiarity with a foreign country can significantly lower communication costs. They possess valuable information about the market structure, consumer preferences, business ethics and commercial codes in both economies. They decrease the costs of negotiating and enforcing a contract through their social links, networking skills and knowledge of the local legal regime. In short, business and social networks that span national borders can help to overcome many contractual and informational barriers and carry out mutually beneficial international transactions. ${ }^{1}$

Foreign direct investment activities may face even larger information asymmetries than international trade transactions. Direct investment generally requires long-term focus and interactions with diverse group of economic agents from suppliers and workers to government

\footnotetext{
${ }^{1}$ Gould (1994) finds that both US exports and imports are positively correlated with the stock of migrants from the partner country present in the US. Head and Ries (1998) reach a similar conclusion when examining Canadian data, as do Combes et al. (2003) using information on intra-regional economic activity in France. Rauch and Trindade (2002) distinguish between the effect of networks as a conduit of information and a contract enforcement mechanism. They show that the presence of ethnic Chinese networks matters more for trade in differentiated products than for trade in homogenous commodities. Given that it is harder to assess the attributes of differentiated products, these findings suggests that in addition to serving as an information channel, ethnic networks may provide implicit contract guarantees and deter opportunistic behavior among its members. See a survey of the literature by Rauch (2001) for more details.
} 
officials. The investor needs to have detailed knowledge of the consumer, the labor and input markets and the legal and regulatory regimes in the host country. Contractual and informational problems can be quite severe and that is why variables related to governance and legal regimes are found to be among the most important determinants of FDI flows into a country. ${ }^{2}$ Thus, it is natural to expect a positive relationship between migration and FDI, yet surprisingly this is a relatively unexplored area. ${ }^{3}$ The only studies examining this question are unpublished papers by Bhattacharya and Groznik (2003) and Buch et al. (2003), which find a positive relationship between migration and FDI flows, and a forthcoming study by Kugler and Rapoport (2006), whose results suggest that migration and FDI inflows are negatively correlated contemporaneously but that skilled migration is associated with an increase in future FDI. ${ }^{4}$

This paper contributes to the literature by explicitly taking into account the endogeneity problem that has been ignored in the existing studies. ${ }^{5}$ Endogeneity arises since migration and FDI flows may influence each other. On the one hand, as FDI inflows bring capital, new technologies and know-how to host countries, they may lead to faster economic growth (provided some conditions are fulfilled, see Alfaro et al. 2004). Entry of multinationals also tends to produce better employment opportunities and higher paying jobs (Lipsey and Sjoholm 2004). Therefore, FDI inflows may lower the incentives to migrate. On the other hand, the presence of FDI may have a positive effect on migration as local employees may be transferred by their

\footnotetext{
${ }^{2}$ See for instance, Wei (2000) and Smarzynska and Wei (2000).

${ }^{3}$ The importance of migrant networks for FDI flows is reflected in anecdotal evidence. For instance, Singh (2003) reports: "Many times top management of Indian origin in the U.S. was asked to start up the offices in India, usually in emerging industrialized cities such as Bangalore and Hyderabad. For example, a return migrant who had worked for Yahoo office in the U.S. for five years set up Yahoo's development center in Bangalore. This returnee had made the personal decision of moving back to India with his family but ideally wanted to do the same work in India he was currently doing with Yahoo in the San Francisco Bay Area. His managers at Yahoo created a proposal for a new development center in Bangalore to be run by this returnee. After some negotiations the proposal was accepted by the executives of Yahoo and he soon was in charge of opening up a Yahoo development in India. This happened because Yahoo management in the U.S. valued his work and recognized his potential in creating a development center in India."

The results of a recent survey of Indian software industry show that $14 \%$ of firms received investment from Indians domiciled in a developed country and in a quarter of those cases, such investment accounted for over half of new investment (Commander et al. 2004).

${ }^{4}$ Kugler and Rapoport regress the growth in capital financed with US FDI in country k in the 1990s on the stock of migrants from country k present in the US in year 1990 and the change in this stock taking place between 1990 and 2000. They use three dependent variables: total FDI, FDI in manufacturing and FDI in services. They also distinguish between migrants with primary, secondary and tertiary education. They use information on 55 countries and find a positive relationship between total US FDI and the 1990 stock of migrants with primary and tertiary education and no significant relationship for the change in migrant stocks. When FDI in manufacturing is considered, the 1990 stock of migrants with tertiary education appears to have a positive effect, while the change in the stock of migrants with secondary education is associated with lower FDI. In the case of services, the stock of migrants with tertiary education appears to have a positive effect on FDI, and the change in this stock negatively affects FDI.

${ }^{5}$ To assess causality Buch et al. (2003) use the Arellano-Bond approach, however, the tests of overidentifying restrictions reject the validity of this approach.
} 
foreign employer to the company headquarters abroad or their experience of working for a multinational may later facilitate their move to the foreign employer's home country. These effects are likely to be stronger for highly educated workers who have the skills to work for foreign multinationals and this would explain, the stronger relationship between FDI flows and skilled migration. Yet none of the existing studies mentioned above has addressed this potentially critical issue.

In this study, we examine the relationship between the presence of migrants in the United States and US foreign direct investment in 56 countries around the world. To address the potential endogeneity of migration with respect to FDI, we employ the instrumental variable approach. Our instruments include the stock of migrants in the European Union (EU), the costs of acquiring a national passport in the migrants' country of origin and the population density in themigrants' country of origin. As stocks of migrants in major destination countries tend to be correlated, the first instrument is likely to be a good predictor of migrant presence in the US. As for the second instrument, McKenzie shows (2005) that high passport costs are associated with lower levels of outward migration and tend be correlated with other emigration barriers imposed by countries. Finally, population density has been shown to be an important push factor stimulating emigration as argued by Lucas (2005).

Our results can be summarized as follows. The data suggest that the presence of migrants in the US increases the volume of US FDI in their country of origin. The effect appears to be stronger for skilled migrants, that is, those with at least a college education. The magnitude of the effect is economically meaningful, as a one percent increase in the migrant stock is associated with a 0.3 percent increase in the FDI stock. A similar increase in the number of migrants with tertiary education increases FDI by 0.4 percent. Furthermore, a 10 percent rise in the share of tertiary educated migrants (while keeping total number of migrants constant) increases the FDI stock in their country of origin by an additional 0.5 percent. Our analysis also suggests that ignoring the endogeneity issue tends to underestimate the effect of migration on FDI thus suggesting that foreign investment may reduce the incentives to emigrate.

Migration of educated people (the so-called brain-drain), particularly from developing countries to developed ones, is generally perceived as having a negative effect on the home country. This effect may be somewhat mitigated by flows of remittances from migrants, which generate significant income for many developing countries. Our results suggest that there may exist another positive effect of migration; migrant diaspora may serve as a channel of information transfer across international borders and thus may contribute to greater integration of their home country with the global economy through larger presence of FDI. 
We also contribute to the literature on the linkages between factor mobility and international trade. Factor mobility and trade emerge as substitutes or complements in various models depending on the underlying assumptions on technology, factor endowments and mobility. ${ }^{6}$ Our results indicate that the relationships between the movements of the underlying factors of production - labor and capital in this case - also need to be taken into account and in this case appear to be complements.

The following section describes the data and the empirical strategy. Next we discuss the results. The final section presents the conclusion.

\section{Estimation Strategy}

The basic question we seek to address is whether, aside from the general determinants of FDI flows, such as partner country specific characteristics, the volume of US FDI abroad is also influenced by the stock of migrants from the partner country present in the US. To examine this question we start with a basic specification:

$$
\ln F D I_{c t}=\alpha+\delta_{l} \text { ln Migrants }_{c t}+X_{c t} \Pi+\alpha_{t}+\varepsilon_{c t}
$$

where the dependent variable is the stock of US FDI in country $c$ at time $t$ measured in terms of (i) the value of total assets of non-bank affiliates of non-bank US parents, or (ii) the volume of sales of non-bank affiliates of non-bank US parents. The dependent variable enters the equation in the log form. The explanatory variable of interest is the logarithm of the stock of migrants from country $c$ present in the US at time $t$. Depending on the specification, we use the information on the total stock of migrants, the stock of migrants with at least tertiary education or both the total stock of migrants and the share of migrants with tertiary education. ${ }^{7}$ The information on FDI and migrants is available for two years: 1990 and 2000.

We include several partner country specific control variables commonly used in the literature on FDI determinants. These are: $\log$ of population size to capture the potential market size of the country, log of GDP per capita to proxy the purchasing power of consumers in the country, the average inflation during the 5 year period to control for macroeconomic stability, an index of the quality of the business climate, a dummy for the presence of armed conflict in the 1990s, log of distance to the US to capture the transaction costs related to travel, communications costs and cultural distance and a dummy for the year $1990\left(\alpha_{t}\right)$.

\footnotetext{
${ }^{6}$ For example, Markusen (1986) argues that substitutability is a special case of factor proportions models. ${ }^{7}$ Since taking the logarithm would lead to losing all observations for which the total stock of migrants or the stock of migrants with tertiary education take the value of zero, we add one before taking the log.
} 
As we are concerned about the endogeneity of the migrant stock, we employ the instrumental variable approach. Our first instrument is the stock of migrants from country $c$ living in the European Union (EU) at time $t$. Given that both the US and the EU are major destinations for migration flows, the stocks of migrants in the US and EU will be correlated. However, there is less reason to suspect that the stock of migrants in the EU is correlated with the error term in the regression. ${ }^{8}$ The definition of this instrument corresponds to the definition of the variable for which it is instrumenting. An aggregate migrant stock in the US is instrumented using the aggregate migrant stock in the EU, and the stock of college educated migrants in the US is instrumented with the stock of college educated migrants in the EU.

Our second instrument is the cost of obtaining a national passport in the partner country $c$, normalized by the country's GDP per capita. High passport fees are likely to constitute a barrier to emigration, particularly for the poorer segment of the population. Indeed, McKenzie (2005) finds that high passport fees are associated with lower levels of outward migration.

As the third instrument, we use the log of population density in the partner country c. Earlier migration research has shown that population density is an important push factor, especially in countries with significant rural populations, as it reflects the absence of adequate land ownership.

We also experiment with two additional instruments capturing legal barriers to obtaining a passport and traveling out of the country faced by citizens of some countries. For instance, in some countries married women need to obtain permission from their husband and unmarried women need to obtain permission from their father or an adult relative in order to travel abroad. Such legal restrictions are often accompanied by a social disapproval of women migrating alone. As McKenzie (2005) shows, the presence of such restrictions is negatively correlated with the number of migrants relative to the population size. The second set of restrictions pertains to the need to obtain government permission or an exit visa to travel abroad and to travel restrictions imposed on citizens of national service age. Although the permission to travel may be granted in most cases, the existence of restrictions adds to the costs and uncertainty of the migration decision. Moreover, the restrictions imposed on citizens of national service age may constrain the population in the age range at which individuals have the greatest propensity to migrate (McKenzie 2005).

\footnotetext{
${ }^{8}$ While countries experiencing a military conflict or a major economic crisis are likely to experience both an increase in emigration and a decline in FDI inflows, this phenomenon would be captured by the other control variables in our regression.
} 


\section{Data}

The data used in this study come from several sources. The source of migration figures is the US Census, which includes very detailed information on the social and economic status and the country of origin of foreign-born individuals living in the United States. We use the information from the $1 \%$ sample of the 1990 and the 2000 Census. ${ }^{9}$ Each individual observation in the Census has a population weight attached to it, which captures the proportion of the overall US population the observation represents. Thus, foreign-born individuals in our data represent around 4.5 million people in the US. The data also contain information about the individual's industry of employment and the education level. There are 9 separate education levels listed in the Census, and we divide them into two main categories: (i) college or above and (ii) less than college education. Thus we are able to calculate the stock of migrants from each country of origin in each educational category present in the US in 1990 and 2000.

As a robustness check, we also use information on the migrant's industry of employment. There are close to 300 industries listed in the Census, and we aggregate them into ten sectors to match the sectoral FDI data. Based on the information on an individual's age and year of arrival, we construct their date of entry into the US labor market. ${ }^{10}$ In this way, we construct the migrant stock for each industry, year and country of origin.

Information on US FDI abroad comes from the Bureau of Economic Analysis, which collects figures on total assets and sales volume of non-bank affiliates of non-bank US companies. In our main specification, we focus on aggregate figures for each host country but in a robustness check we also estimate a model at the sectoral level. The data can be disaggregated into 10 industries which are finance, food, information technology, chemicals, electronic and electrical equipment, machinery, fabricated metals, wholesale trade, transportation equipment, and services. As the industry classification changed in 1998, we include only those industries that were present throughout the whole period. To match the availability of the Census information on the country of origin as well as the timing of the Census data, we focus on figures for 57 host countries for the years 1990 and 2000.

Turning to other host country characteristics, figures on the population size, GDP per capita in current US dollars and consumer price inflation have been taken from the World Bank's World Development Indicators. For 1990 we use the average of inflation from 1988 through

\footnotetext{
${ }^{9}$ Extracts from the Census samples are made available through IPUMS (Integrated Public Use Microdata Series), which is a database maintained by Minnesota Population Center at University of Minnesota (http://beta.ipums.org/usa/index.html).

${ }^{10}$ We consider the year of arrival and the year of the completion of the highest education degree and take the larger of the two numbers as the year of entry into the US labor market.
} 
1992, and for 2000 the average from 1998 through 2002. Quality of the business climate is measured using the average of the following governance indicators developed by Kaufman, Kraay and Mastruzzi (2004): voice and accountability, political stability, government effectiveness, regulatory quality, rule of law, and control of corruption. The indicators are available for alternating years in the 1996-2004 period. They range from -2.5 to 2.5 with higher numbers corresponding to higher quality of governance in the country. For 1990 we use the 1996 data and for 2000 we use 2000 data. The conflict indicator is an index constructed based on information available at www.prio.no, "Armed Conflict Version 2.1." by Gleditsch, Wallensteen, Eriksson, Sollenberg and Strand (2002). The index takes on values from 0 (no conflict) to 3 (severe conflict) depending on the depth of the conflicts in which the country was involved during the 1990s. The distance between the US and the partner country is measured in miles and comes from Andrew Rose's dataset available at http://faculty.haas.berkeley.edu/arose/.

In our instrumental variables approach, we use data on migrant stocks in the 15 countries of the European Union disaggregated by country of origin and education level, taken from Docquier and Marfouk (2005). We employ the information on passport fees from McKenzie (2005). We normalize the fees by the country's GDP per capita expressed in US dollars. ${ }^{11}$ Finally, we use the data on population density from the World Development Indicators database.

As additional instruments, we employ a dummy variable taking the value of one for countries in which women face restrictions on foreign travel and a dummy variable taking the value of one for countries placing other legal restrictions on emigration. There are only two countries in the sample which employ the first type of restrictions (Egypt and Saudi Arabia) and four countries with the second type of restrictions (Ecuador, Equatorial Guinea, Israel where government permission is required to travel and Singapore which restricts travel of citizens of national service age). Moreover, due to a regrettable mismatch in timing, as these variables pertain to year 2004/5, we use these additional instruments only in a robustness check. Both variables come from McKenzie (2005).

Table 1 presents summary statistics of all variables used in the study.

\footnotetext{
11 The information on fees pertains to 2005. To make the figures comparable to the GDP per capita data we express the fees in 1990 and 2000 US dollars, as appropriate.
} 


\section{Results}

\subsection{OLS specification}

We begin our analysis with a basic OLS model and present the results for three sets of regressions. Each set uses a different definition of the migration variable and within each set we employ two alternative dependent variables: total assets of US affiliates abroad and sales of US affiliates abroad. In the first set of regressions (columns 1 and 2 in Table 2), the variable of interest is the total stock of migrants from the partner country $c$ present in the US at time $t$. The second set uses the stock of country $c$ 's migrants with tertiary education living in the US at time $t$ (columns 3 and 4), and the third set employs both the aggregate stock of migrants from the partner country $c$ present in the US at time $t$ as well as the share of tertiary educated migrants in the total stock of migrants from the partner country $c$ present in the US at time $t$ (5 and 6).

The presence of migrants with a college education appears to be positively correlated with US FDI in their country of origin. This effect is significant at the 10 percent level in both specifications. In contrast, the aggregate stock of migrants does not have a statistically significant effect on either of the FDI variables. When two indicators of migration (total migrant stock and the share of college educated migrants) are entered into the same model, both bear positive signs but neither variable reaches conventional significance levels.

Based on the OLS regression, it could be inferred that the presence of tertiary educated migrants in US plays a role in FDI flows from the US to the origin countries of the migrants. Total migration seems to have no discernible effect on FDI. However, these estimations are likely to distort the true effect of migration on FDI, because they ignore the endogeneity that may be present between FDI stocks and migration. To account for this possible endogeneity, we use the instrumental variable approach in the following section.

The other control variables have the expected signs. We find that countries with large markets (in terms of population size and GDP per capita) attract more FDI. Both variables are significant at the one percent level. The same is true of countries located closer to the US, albeit this variable is not significant in all specifications. While the other control variables bear the anticipated signs, they are not statistically significant with the exception of the time dummy which suggests that FDI stock in 2000 exceeded that of a decade earlier. The regressions have a satisfactory explanatory power with the R-squared ranging from .76 to .81 .

Our data also allow us to repeat the above exercise at the sectoral level. ${ }^{12}$ More precisely, we regress the stock of FDI in sector $s$ in country $c$ at time $t$ on the presence of migrants from

\footnotetext{
${ }^{12}$ Recall the anecdotal evidence mentioned in footnote 3.
} 
country $c$ employed in sector $s$ in the US at time $t$. The model includes partner country and industry fixed effects. Standard errors are clustered at the country-industry level. The results, presented in Table 3, differ from those obtained earlier. In all six regressions, we find a positive and significant coefficient on the stock of migrants employed in the sector. This is the case for the stock of migrants regardless of their educational background as well as for the stock of migrants with tertiary education. Moreover, when the total sectoral stock is entered jointly with the share of educated migrants, we find that both variables bear positive and statistically significant coefficients.

\subsection{Instrumental variable approach}

Next we employ the instrumental variable approach and present the first and the second stage results in Tables 4 and 5, respectively. Our baseline set of instruments includes: the presence of migrants in the EU (total stock, stock of tertiary educated migrants or share of tertiary educated migrants in total stock, depending on the specification), population density in the migrants' country of origin and the cost of obtaining a national passport normalized by GDP per capita in the migrants' country of origin. As a robustness check, in the last two specifications we also present results with additional instruments (restrictions on womens' travel and other legal restrictions on emigration).

As illustrated in Table 4, our instruments perform quite well as they can explain a significant portion, between $14 \%$ and $36 \%$, of the variable they are instrumenting for, i.e. the aggregate stock of migrants or the stock of migrants with tertiary education. Their suitability is also confirmed by the test of excluded instruments and the overidentification tests. All instruments have the expected sign. While a higher population density and a larger migrant stock in the EU are positively correlated with the presence of migrants in the US, a negative correlation is found between the passport cost, restrictions on women's travel and the migration variable.

The partner country specific control variables in the second stage (Table 5) exhibit the same sign and significance pattern as in the OLS specification. The only exception is the distance, which has ceased to be statistically significant in all but one specification.

Large differences, however, appear with respect to migration. As we have corrected for the endogeneity of the migration variables, their coefficients should reflect reality to a greater extent than the coefficients in the OLS regressions. We find that both aggregate migrant stock as well as the stock of migrants with tertiary education are positively correlated with the stock of US FDI in the migrants' country of origin. The coefficients on migrant stocks are statistically significant in all 8 specifications. The elasticity of FDI with respect to migration is higher for 
skilled migrants, which is intuitive as college educated migrants may be better positioned both financially and socially to assist US companies and entrepreneurs in investing abroad. This pattern is confirmed in the last four specifications where both the aggregate migrant stock and the share of skilled migrants have positive and statistically significant coefficients.

The magnitudes of these effects are economically meaningful. A one percent increase in the total migrant stock is associated with a .3 percent increase in the FDI stock. In the case of skilled migrants, the corresponding effect is higher reaching about .4 percent. Using the last two specifications as the basis for inference, we find that a 10 percent rise in the share of tertiary educated migrants in the migrant population increases the FDI stock in their country of origin by an additional .57 percent.

We conclude that there exists a positive correlation between the presence of migrants in the US and the stock of FDI in their country of origin. This correlation is particularly strong in the case of migrants with college education. Our analysis also suggests that ignoring the endogeneity issue tends to underestimate the effect of migration on FDI.

\subsection{Robustness checks}

To check the robustness of our results, we reestimated all regressions excluding Mexico, which has a special status vis-à-vis the US relative to other destination countries included in the analysis, both as a sender of migratory flows and as a recipient of FDI. The special relationship between the US and Mexico is due to their geographic proximity, membership in NAFTA as well as from a large differential in the level of economic development between the two neighbors which prompts a large number of Mexicans to cross the border in search of a better life. The results, presented in Appendix Tables A1 (OLS - aggregate FDI flows), Table A2 (OLS - sectorlevel FDI flows) and Table A3 (IV regressions) do not differ significantly from the results of the orginal model. Therefore, we conclude that our findings are not driven by the figures for Mexico.

\section{Conclusions}

The purpose of this study was to examine whether migrant networks have a positive effect on flows of foreign direct investment to the migrants' country of origin. To study this question, we used data on US FDI abroad and the presence of migrants in the US. To take into account the potential simultaneity between FDI and migrant flows, we instrumented for the migrant presence in the US using information on the stock of migrants from the country of origin 
present in the EU, population density in the migrants' country of origin, the cost of obtaining a national passport and other legal barriers to emigration in the migrants' country of origin.

Our results suggest that US FDI abroad is positively correlated with the presence of migrants from the host country. This finding is consistent with the hypothesis that ethnic networks serve as an important channel of information about business conditions and opportunities abroad, which was postulated and confirmed in the context of the international trade literature. Our findings further indicate that the relationship between FDI and migration is driven by the presence of migrants with a college education, thus suggesting that the presence of an educated diaspora may have a positive effect on the integration its country of origin with the global economy. 


\section{Bibliography}

Alfaro, Laura, Areendam Chanda, Sebnem Kalemli-Ozcan, and Selin Sayek. 2004. "FDI and Economic Growth: The Role of Local Financial Markets," Journal of International Economics 64(1).

Buch, Claudia, Jörn Kleinert and Farid Toubal. 2003. "Where Enterprises Lead, People Follow? Links Between Migration and German FDI,” Kiel Working Paper No. 1190.

Bhattacharya, Utpal and Peter Groznik. 2003. "Melting Pot or Salad Bowl: Some Evidence from U.S. Investments Abroad,”. EFA 2003 Annual Conference Paper No.650.

Commander, Simon, Rupa Chanda and L. Alan Winters. 2004. "Who Gains from Skilled Migration? Evidence from the Software Industry," London Business School mimeo.

Docquier, Frederic and Abdeslam Marfouk. 2005. "Measuring the international mobility of skilled workers (1990-2000)," World Bank Policy Research Working Paper No. 3381.

Gleditsch, Nils Petter, Peter Wallensteen, Mikael Eriksson, Margareta Sollenberg \& Håvard Strand. 2002. "Armed Conflict 1946-2001: A New Dataset," Journal of Peace Research 39(5): 615-637.

Gould, David M. 1994. "Immigrant Links to the Home Country: Empirical Implications for U.S. Bilateral Trade Flows," Review of Economics and Statistics, 76: 302-16.

Head, Keith and John Ries. 1998. "Immigration and Trade Creation: Econometric Evidence from Canada," Canadian Journal of Economics, 31(1): 47-62.

Kaufmann, Daniel; Kraay, Aart; Mastruzzi, Massimo. 2004. „Governance matters IV: governance indicators for 1996-2004,” World Bank Policy Research Working Paper No. 3630.

Kugler, Maurice and Hillel Rapoport. 2006. "Skilled Emigration, Business Networks and Foreign Direct Investment," Economic Letters, forthcoming.

Lipsey, Robert E. and Fredrik Sjoholm. 2004. Foreign direct investment, education and wages in Indonesian manufacturing Journal of Development Economics, 73(1): 415-422.

Lucas, Robert E.B. 2005. International Migration and Economic Development: Lessons from Low Income Countries, Regeringskanliet, Sweden.

Markusen, James. 1986. "Explaining the Volume of Trade: An Eclectic Approach," American Economic Review, 76(5): 1002-1011.

McKenzie, David. 2005. "Paper Wall Are Easier to Tear Down: Passport Costs and Legal Barriers to Emigration," World Bank Policy Research Working Paper No. 3783.

Rauch, James. 2001. "Business and Social Networks in International Trade," Journal of Economic Literature, XXXIX: 1177-1203.

Rauch, James and Vitor Trindade. 2002. "Ethnic Chinese Networks In International Trade, Review of Economics and Statistics 84(1): 116-130

Singh, Shinu. "Economic Impact of Return Migration of Highly-Skilled IT Professionals from the United States to India," Draft Thesis, Massachusetts Institute of Technology (downloaded on August 18, 2006 from http://web.mit.edu/nruiz/www/Documents/Shinu's\%20Thesis\%20Draft.pdf\#search=\%22 Shinu\%20Singh\%20india\%20migration\%22) 
Smarzynska, Beata and Shang-Jin Wei. 2000. "Corruption and Composition of Foreign Direct Investment: Firm Level Evidence" with Shang-Jin Wei, World Bank Policy Research Working Paper No. 2360.

Wei, Shang-Jin. 2000. "How Taxing Is Corruption on International Investors?" Review of Economics and Statistics. 82 (1): 1-11. 


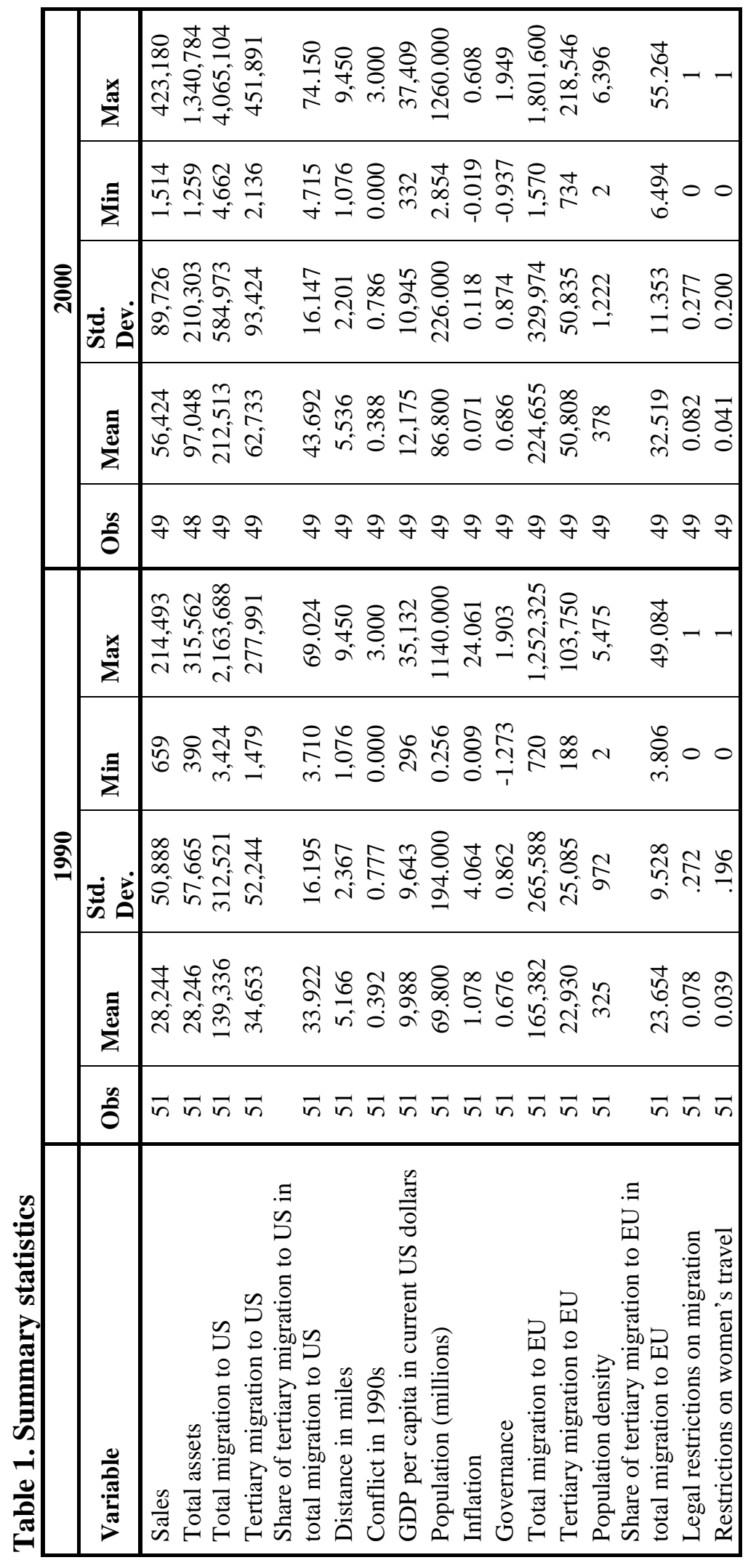




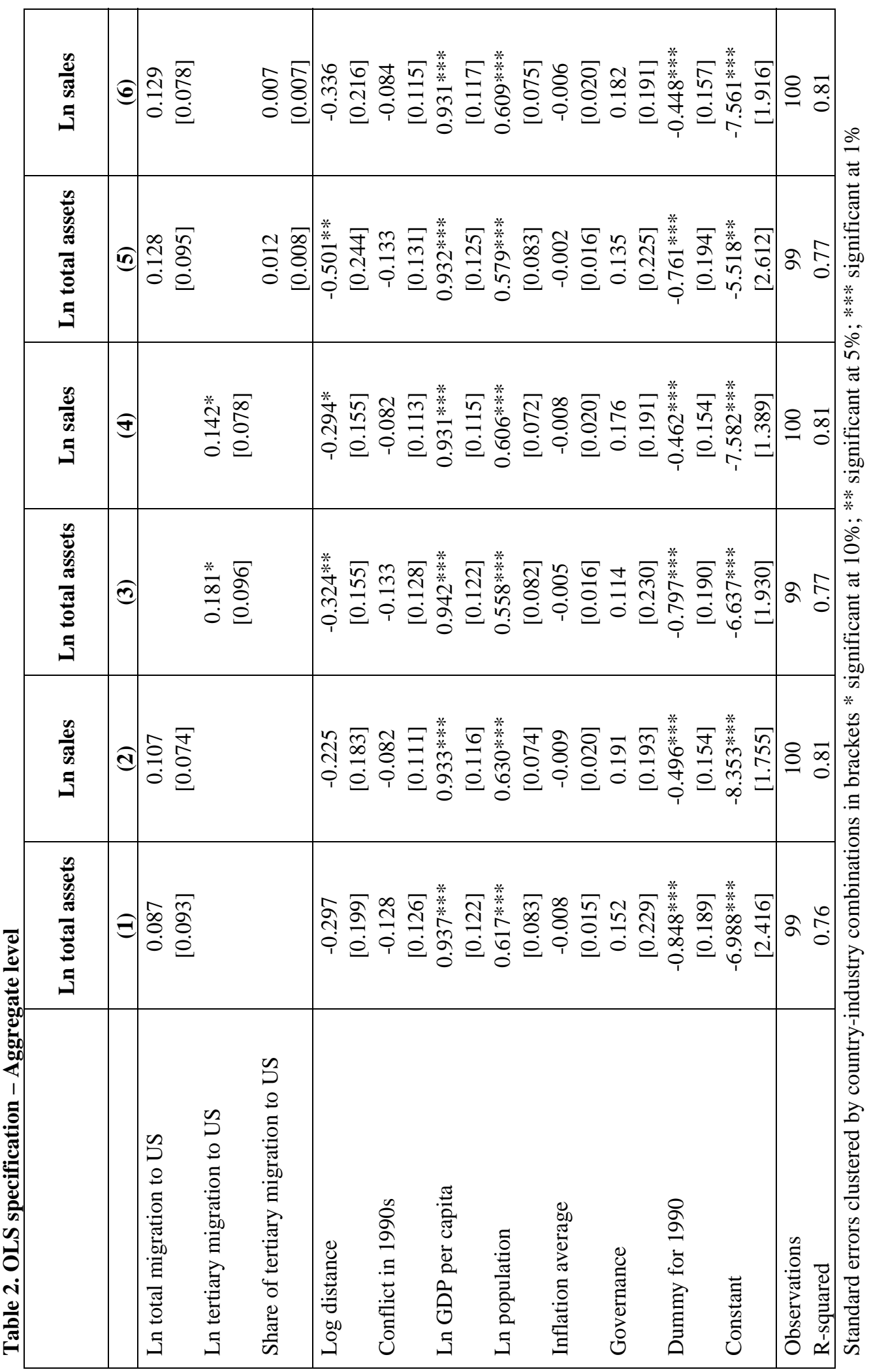




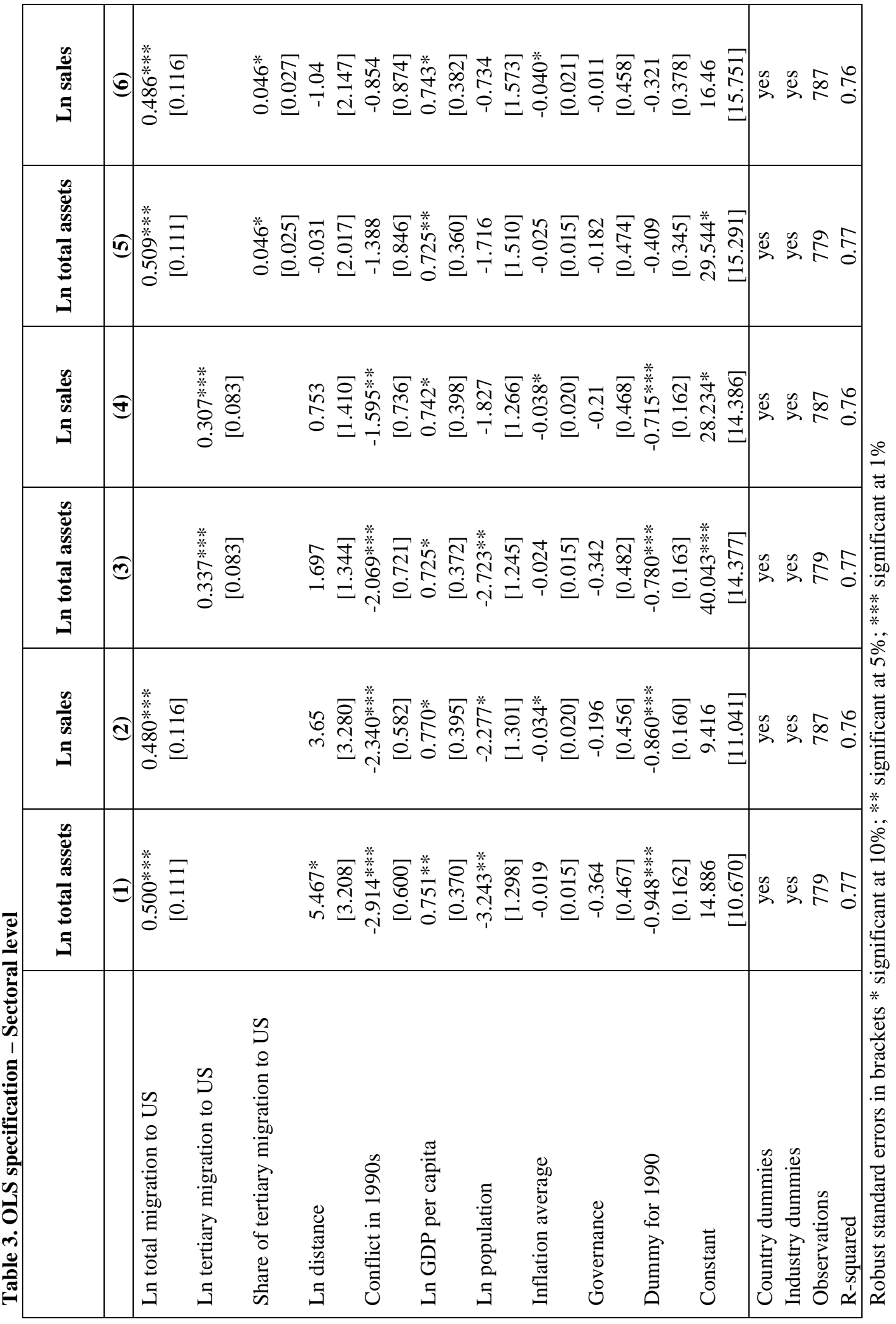




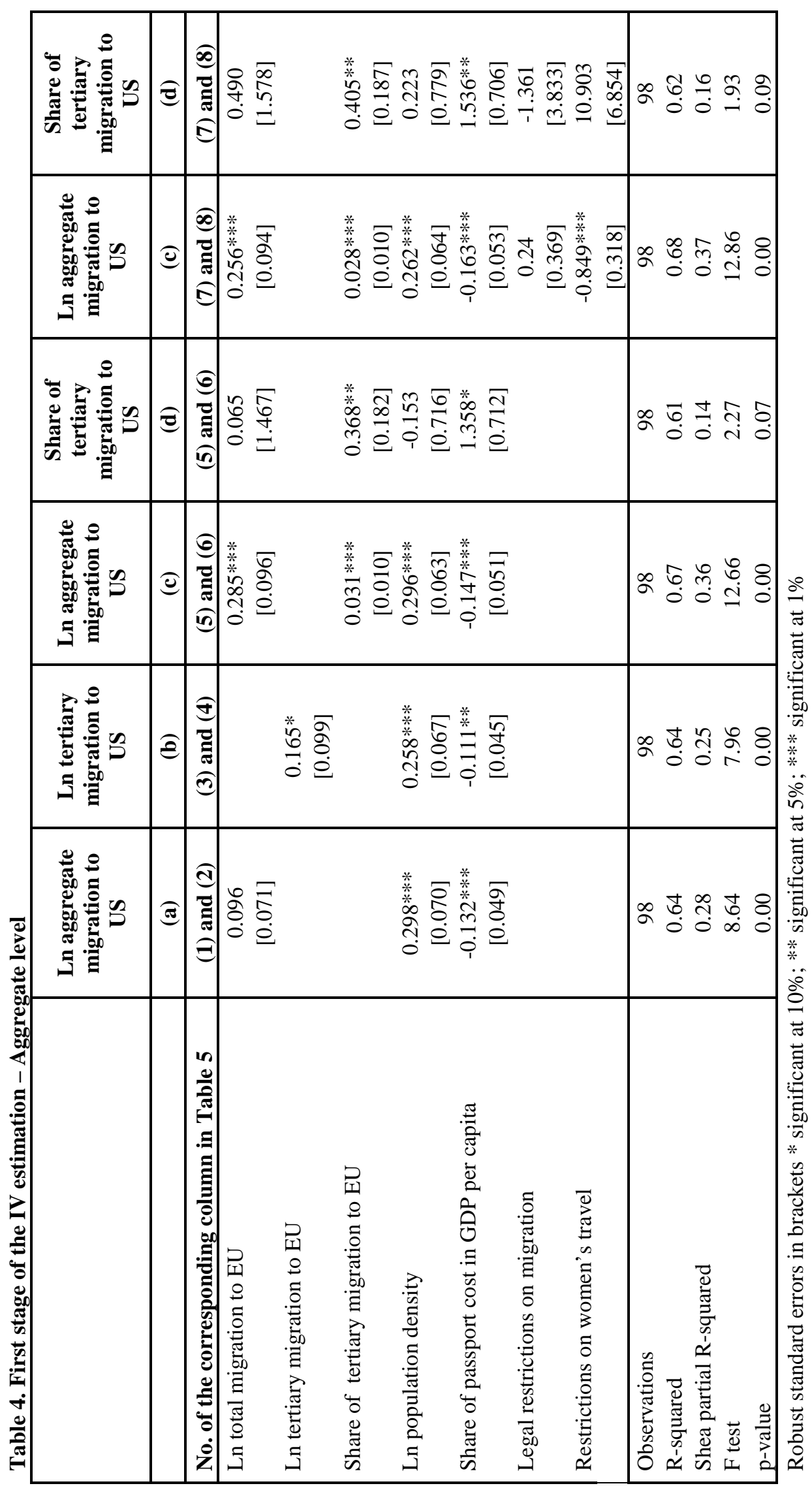




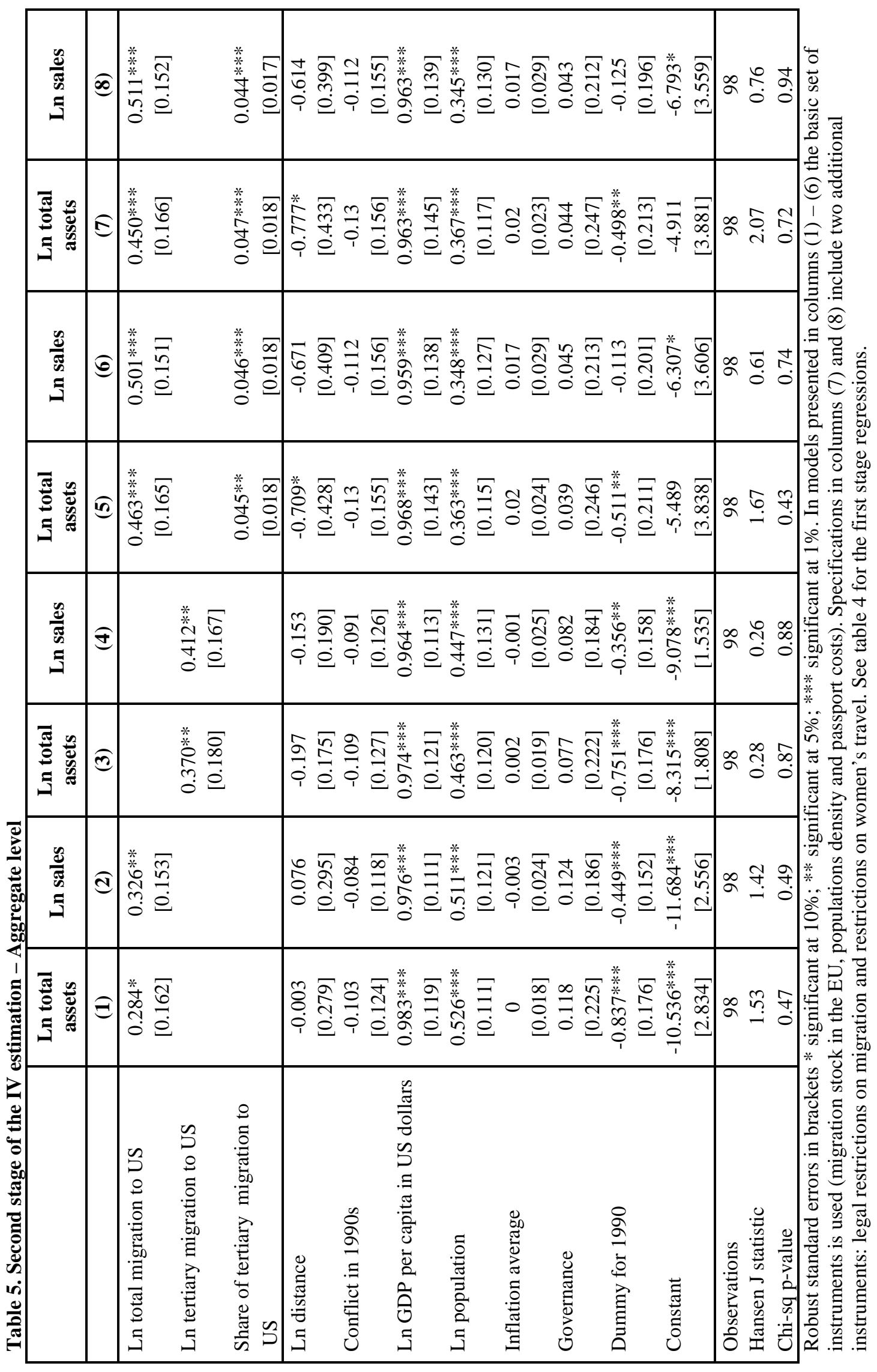




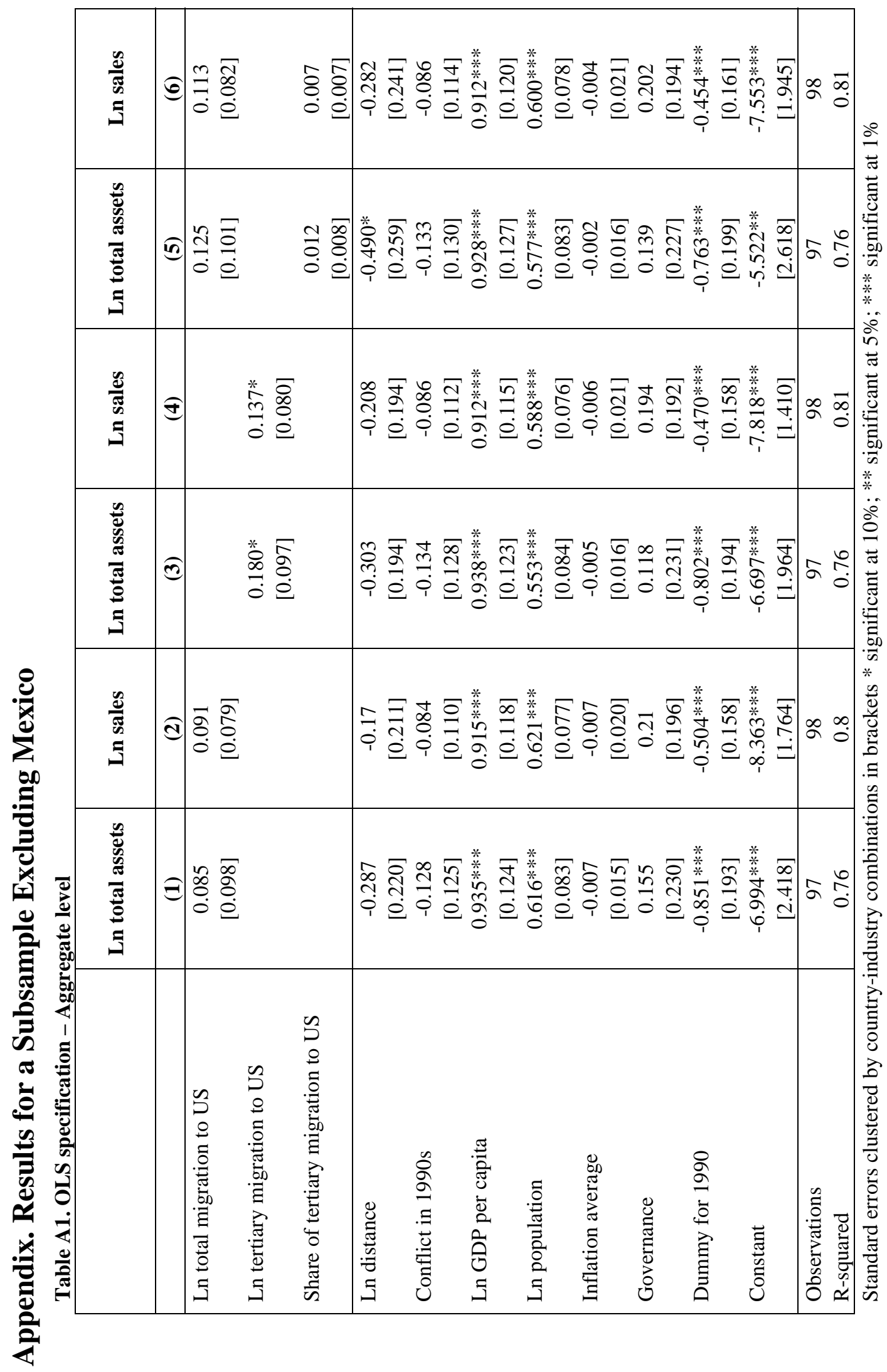




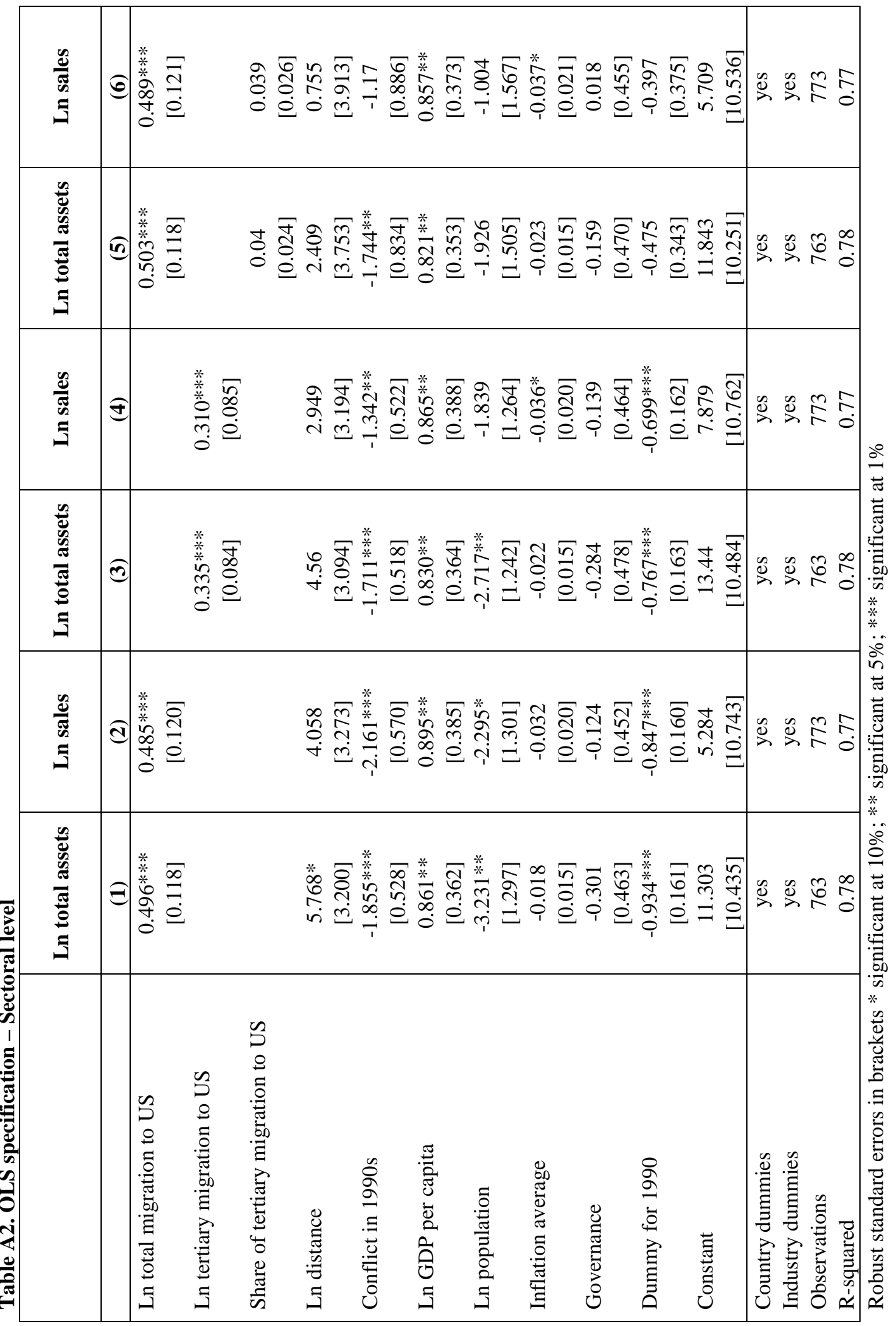




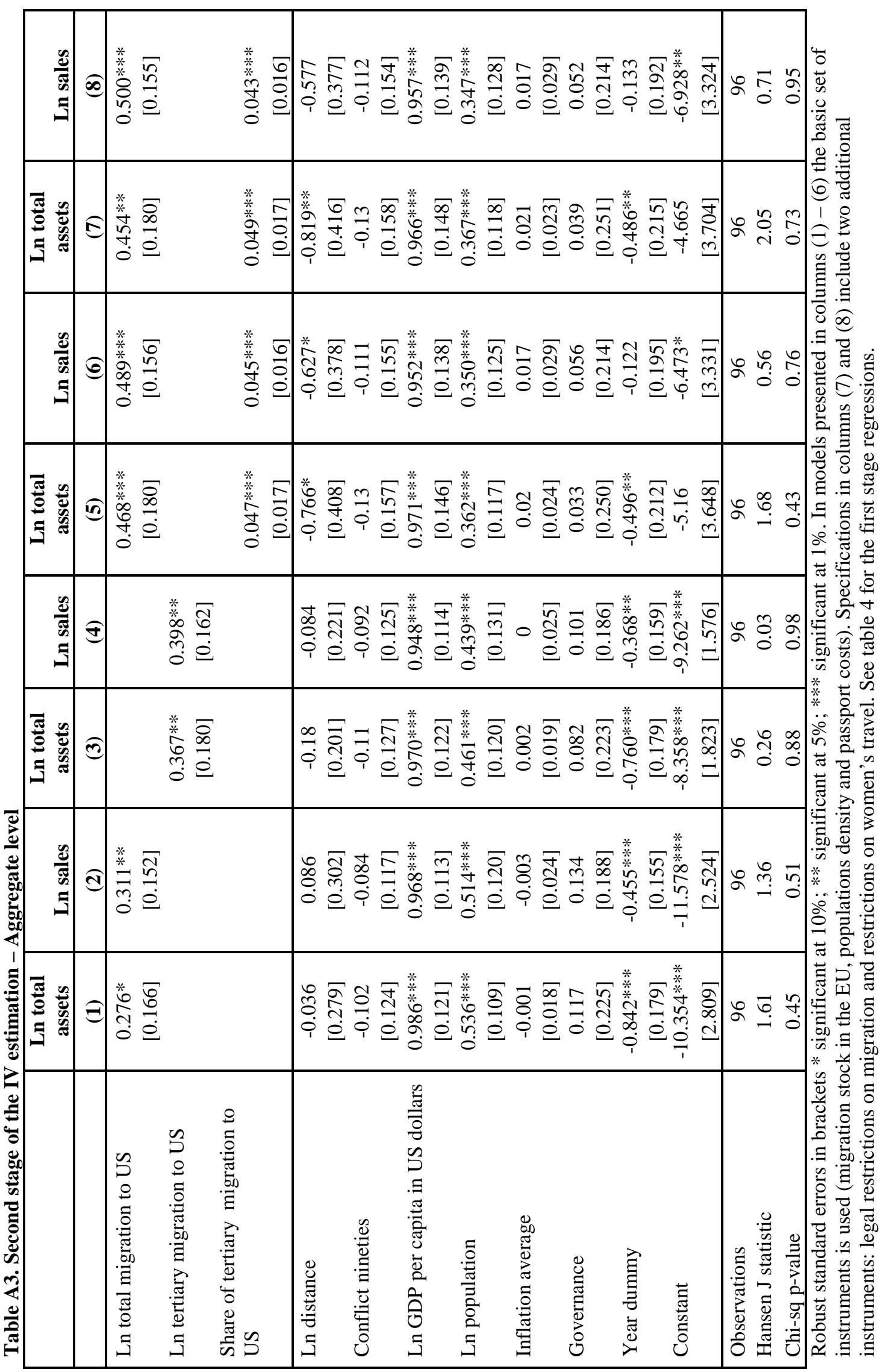


